\title{
Disparity in clinical care for patients with inflammatory bowel disease between specialists and non-specialists
}

\author{
Tomoko Hirakawa $^{1}$, Jun Kato ${ }^{2}$, Sakuma Takahashi ${ }^{1}$, Hideyuki Suzuki ${ }^{1}$, Mitsuhiro Akita ${ }^{1}$, \\ Izumi Inoue $^{2}$, Hisanobu Deguchi ${ }^{2}$, Sakiko Hiraoka ${ }^{1}$, Hiroyuki Okada ${ }^{3}$, Kazuhide Yamamoto ${ }^{1}$ \\ ${ }^{1}$ Department of Gastroenterology and Hepatology, Okayama University Graduate School of Medicine, Dentistry and Pharmaceutical \\ Sciences, Okayama, Japan \\ ${ }^{2}$ Second Department of Internal Medicine, Wakayama Medical University, Wakayama, Japan \\ ${ }^{3}$ Department of Endoscopy, Okayama University Graduate School of Medicine, Dentistry and Pharmaceutical Sciences, Okayama, \\ Japan \\ Email: tomokoh@t.okadai.jp
}

Received 25 October 2012; revised 24 November 2012; accepted 1 December 2012

\section{ABSTRACT}

Background: Although inflammatory bowel disease (IBD) patients have been increasing and new therapeutic options for IBD have been developed, there are relatively few clinicians who specialize in IBD. Patients treated by a non-specialist of IBD may not receive appropriate treatment. This study aimed to compare disease and medication status between IBD patients treated by a specialist and those treated by a non-specialist. Methods: Medical charts of ambulating IBD patients in two hospitals were examined. All patients in one hospital were treated by one of the IBD specialists, while in the other hospital, patients were treated by one of the gastroenterologists who was a non-specialist of IBD. Results: The numbers of IBD patients were 255 (hospital with specialists) and 74 (hospital without specialists), respectively. Disease activity of the patients was not well-controlled in the hospital without specialists compared to in the hospital with specialists (ulcerative colitis (UC): $p=0.0006$ and Crohn's disease: $p=0.012$, respectively). The proportion of UC patients who received an insufficient dose of mesalazine (Pentasa $<3$ g/day or Asacol $<3.6 \mathrm{~g} /$ day) was higher in the hospital without specialists $(47 \%$ vs. $15 \%, p<0.0001)$. In the hospital without specialists, more patients received long-term corticosteroids (UC: $23 \%$ vs. $5 \%, p<0.0001$ ), while fewer patients received immunomodulators (UC: $8 \%$ vs. $46 \%, p<0.0001)$. Conclusions: IBD patients of the hospital without specialists were not well-controlled and were not prescribed appropriately with therapeutic drugs. Fostering and placement of the specialist of IBD is an urgent problem.

Keywords: Inflammatory Bowel Disease; Clinical Care; Specialist

\section{INTRODUCTION}

Inflammatory bowel disease (IBD) involves ulcerative colitis (UC) and Crohn's disease (CD). UC is a chronic disease characterized by diffuse mucosal inflammation limited to the colon. Meanwhile, CD can affect any part of the gastrointestinal tract with focal, asymmetric, transmural, and occasionally, granulomatous inflammation. Patients of either disease suffer from symptoms such as diarrhea, abdominal pain, bloody stool, etc. unless appropriate treatment is provided. There are approximately 1.4 million and 2.2 million IBD patients in the USA and in Europe, respectively [1-3]. Moreover, in recent years a drastic increase in IBD patients has been noted in Asian countries. In Japan, the numbers of $\mathrm{UC}$ and $\mathrm{CD}$ patients were approximately 23,000 and 6600 in 1990, respectively, while in 2010 , the numbers had increased to more than 120,000 and 30,000, respectively [4,5].

Recently, new therapeutic agents have become available for the treatment of IBD. In particular, new immunomodulators such as cyclosporine, tacrolimus, and biologics such as infliximab and adalimumab have been shown to be effective for aggressive and/or refractory UC and CD [6-11]. On the other hand, although 5-aminosalicylic acid (5-ASA), corticosteroids, and older immunomodulators such as azathioprine and 6-mercaptopurine (AZA and 6-MP) have been widely used, it is rather difficult to make full use of these agents while avoiding adverse effects. Corticosteroids can induce various serious side effects such as hyperglycemia, cushingoid features, infections, osteoporosis, emotional and psychiatric disturbances, gastroduodenal mucosal injury, glaucoma, and cataracts. In addition, patients on chronic corticosteroids are at risk of adrenal insufficiency. Moreover, AZA and 6-MP are also not user-friendly because of frequent adverse effects including leukocytepenia, thrombocytopenia, alopecia, liver abnormalities, 
allergy, uncomfortable gastrointestinal symptoms, and pancreatitis. Thus, more than ever highly specialized knowledge and experience of biological and clinical features of IBD are required for providing appropriate treatment. Therefore, many guidelines have been made and updated by various organizations in the USA [12,13], Europe [14], and also in Japan [15,16].

In spite of these guidelines, however, inappropriate treatments continue to be provided for many IBD patients because of the limited numbers of clinicians specializing in IBD. Even in the USA, considerable numbers of patients who visited an IBD center for the purpose of obtaining a second opinion were inappropriately treated, e.g., with suboptimal doses of 5-ASA and immunomodulators, or with long-term corticosteroid therapy [17]. The situation is much worse in Japan, where there is now a greater gap between the numbers of IBD specialists and IBD patients because of the rapid increase in IBD patients. Because even gastroenterologists are in short supply in Japan, particularly in local areas, there is no optimism in expectations for an increase of IBD specialists.

Thus, recent advances and traditional compassionate care in providing therapeutic options of IBD can make a great difference in the disease and status of IBD patients according to the doctor's skill, knowledge, and experience for IBD. Patients who are provided medications by IBD non-specialists may harbor a poorer disease status. If so, disseminating a standard therapeutic strategy may be much more important than developing various guidelines in various organizations. The purpose of this study was to compare the disease and treatment status of IBD patients who were treated by specialists vs. non-specialists of IBD.

\section{PATIENTS AND METHODS}

\subsection{Patients}

The activity status and medical prescriptions for ambulating IBD patients were compared between two hospitals. The first hospital is Okayama University Hospital in Okayama City, a city with a population of 700,000 located in the western mainland of Japan. The second hospital is Wakayama Medical University Hospital in Wakayama City, a city with a population of 350,000 located in the midwest of the mainland of Japan. Both facilities are tertiary medical centers of each city. All IBD patients were provided medical care by one of the two IBD specialists at the first facility (hospital with specialists), while IBD patients were seen by one of the seven gastroenterologists all of whom were non-specialists of IBD at the second facility (hospital without specialists). The medical records of all IBD patients who visited periodically at each of the two hospitals during the same time point (November 2010) were examined. UC patients who had undergone colectomy were excluded from the analysis.

The analysis of clinical data of patients for medical studies was approved by the Institutional Review Boards of Okayama University Graduate School of Medicine, Dentistry and Pharmaceutical Sciences, and Wakayama Medical University.

\subsection{Study Design}

A review of patient records was conducted by one of the authors at each hospital (T.H. at Okayama University Hospital and J.K. at Wakayama Medical University Hospital). The clinical information obtained from the patient record consisted of patient demographic data, disease duration, extent of disease, disease activity, and medical prescriptions including allergic information at the last hospital visit prior to the date of data collection. Disease activity was evaluated according to the Amerian College of Gastroenterology practice guidelines and European Crohn's and Colitis Organization's grading, and classified into remission, mild disease, moderate disease, and severe disease $[12,13,18]$.

\subsection{Use of 5-ASA}

Brand and daily doses of 5-ASA were investigated. The brands available in Japan were Pentasa, Asacol, and salazosulfapyridine for UC, and Pentasa only for CD. The health insurance in Japan approved $4.0 \mathrm{~g}$ /day of Pentasa and $3.6 \mathrm{~g} /$ day of Asacol as the upper limit doses for UC. The maximum dose allowed of Pentasa for CD was 3.0 $\mathrm{g}$ /day. Use of topical therapy (enema or suppository) was also investigated. Information on allergic history for 5ASA was collected, and patients with histories of allergic reactions for 5-ASA were excluded from the analysis.

\subsection{Use of Corticosteroids, Immunomodulators and Biologics}

Oral corticosteroids use and continuous duration of the drug exposure were investigated. Use of immunomodulators (AZA and 6-MP) and biologics was also investigated. Biologics available in Japan were infliximab and adalimumab for $\mathrm{CD}$, and infliximab only for UC.

\subsection{Statistical Analysis}

Comparison of data from the two institutions was performed by the chi-squared test or Fisher's exact test for categorical variables, and Wilcoxon signed-rank tests for continuous variables. A two-sided $\mathrm{P}$ value of less than 0.05 was accepted as significant. Statistical analysis was conducted using JMP 8 software (SAS Institute, Cary, $\mathrm{NC})$. 


\section{RESULTS}

\subsection{Patient Characteristics}

The numbers of IBD patients who made regular visits to the hospitals at the time of data collection were 255 (hospital with specialists) and 74 (hospital without specialists), respectively. Table 1 summarizes the demographics and disease conditions of the patients. Disease duration was longer in patients of the hospital with specialists than in patients of the hospital without specialists both for $\mathrm{UC}$ and $\mathrm{CD}(p=0.038$ and $p=0.038$, respectively). Extensive colitis, left-sided colitis, and proctitis were nearly evenly distributed among UC patients of the hospital with specialists, while approximately two thirds of UC patients in the hospital without specialists had extensive colitis $(p=0.0007)$.

Table 1. Clinical characteristics of patients.

\begin{tabular}{|c|c|c|c|c|c|}
\hline \multirow[b]{2}{*}{ All IBD patients } & \multicolumn{2}{|c|}{ Hospital with specialists } & \multicolumn{2}{|c|}{ Hospital without specialists } & \multirow[t]{2}{*}{$p$-value } \\
\hline & 255 & & 74 & & \\
\hline UC patients & 187 & & 48 & & \\
\hline \multicolumn{6}{|l|}{ Sex } \\
\hline Men & 94 & $(50 \%)$ & 27 & $(56 \%)$ & \multirow{2}{*}{0.46} \\
\hline Women & 93 & $(50 \%)$ & 21 & $(44 \%)$ & \\
\hline \multicolumn{6}{|l|}{ Age } \\
\hline Median (range) & 41 & $(13-80)$ & 45.5 & $(19-77)$ & 0.17 \\
\hline \multicolumn{6}{|l|}{ Disease duration (year) } \\
\hline Median (range) & 9 & $(0-42)$ & 5.5 & $(0-37)$ & 0.038 \\
\hline \multicolumn{6}{|l|}{ Extent of disease } \\
\hline Extensive colitis & 65 & $(35 \%)$ & 31 & $(65 \%)$ & \multirow{3}{*}{0.0007} \\
\hline Left-sided colitis & 60 & $(32 \%)$ & 10 & $(21 \%)$ & \\
\hline Proctitis & 62 & $(33 \%)$ & 7 & $(15 \%)$ & \\
\hline \multicolumn{6}{|l|}{ Disease activity } \\
\hline Remission & 39 & $(21 \%)$ & 15 & $(31 \%)$ & \multirow{4}{*}{$0.0006^{*}$} \\
\hline Mild & 134 & $(72 \%)$ & 22 & $(46 \%)$ & \\
\hline Moderate & 12 & $(6 \%)$ & 11 & $(23 \%)$ & \\
\hline Severe & 2 & $(1 \%)$ & 0 & $(0 \%)$ & \\
\hline CD patients & 68 & & 26 & & \\
\hline \multicolumn{6}{|l|}{ Sex } \\
\hline Men & 43 & $(63 \%)$ & 18 & $(69 \%)$ & \multirow{2}{*}{0.59} \\
\hline Women & 25 & $(37 \%)$ & 8 & $(31 \%)$ & \\
\hline \multicolumn{6}{|l|}{ Age } \\
\hline Median (range) & 38 & $(19-65)$ & 33.5 & $(17-57)$ & 0.081 \\
\hline \multicolumn{6}{|l|}{ Disease duration (year) } \\
\hline Median (range) & 11.5 & $(2-35)$ & 8 & $(0-25)$ & 0.038 \\
\hline \multicolumn{6}{|l|}{ Extent of disease } \\
\hline Colonic involvement only & 14 & $(21 \%)$ & 4 & $(15 \%)$ & \multirow{3}{*}{0.83} \\
\hline Small bowel involvement only & 16 & $(24 \%)$ & 6 & $(23 \%)$ & \\
\hline Small bowel and colonic dease & 38 & $(56 \%)$ & 16 & $(62 \%)$ & \\
\hline \multicolumn{6}{|l|}{ Disease activity } \\
\hline Remission & 5 & $(7 \%)$ & 2 & $(8 \%)$ & \multirow{4}{*}{$0.012^{*}$} \\
\hline Mild & 53 & $(78 \%)$ & 14 & $(54 \%)$ & \\
\hline Moderate & 10 & $(15 \%)$ & 10 & $(38 \%)$ & \\
\hline Severe & 0 & $(0 \%)$ & 0 & $(0 \%)$ & \\
\hline
\end{tabular}

IBD, inflammatory bowel disease; UC, ulcerative colitis; CD, Crohn's disease. * Disease activity was compared between remission or mild vs. moderate or severe. 
Disease activity of the patients treated at each hospital was in sharp contrast. Patients of the hospital with specialists showed milder activity than patients of the hospital without specialists for both UC and CD (Table 1). In the hospital with specialists, the proportions of the patients in remission or mild activity were $93 \%$ for UC and $85 \%$ for $\mathrm{CD}$, while the proportions of the patients with moderate or severe activity were $7 \%$ for UC and $15 \%$ for CD. In contrast, in the hospital without specialists, the proportions of the patients in remission or mild activity were $77 \%$ for $\mathrm{UC}$ and $62 \%$ for $\mathrm{CD}$, while the proportions of the patients with moderate or severe activity were $23 \%$ for UC and $38 \%$ for CD (hospital with specialists vs. hospital without specialists: $p=0.0006$ for $\mathrm{UC}$ and $p=0.012$ for $\mathrm{CD}$, respectively). These results suggest that the patients of the hospital without specialists were not as well-controlled as the patients of the hospital with specialists.

\subsection{Comparison of 5-ASA Use}

Prescriptions of 5-ASA were compared in patients excluding 19 cases with 5-ASA allergy (Table 2). The proportion of patients using salazosulfapyridine was significantly higher in UC patients of the hospital with specialists than in UC patients of the hospital without specialists $(30 \%$ vs. $7 \%, p=0.0022)$. In UC patients using mesalazine, significantly more patients were prescribed with insufficient doses of the agents (Pentasa $<3$ g/day or Asacol $<3.6 \mathrm{~g} /$ day) in the hospital without specialists than in the hospital with specialists $(47 \%$ vs. $15 \%, p<$ $0.0001)$. This result was almost unchanged when analyzed in patients who had active disease (i.e., excluding patients in remission) ( $52 \%$ vs. $22 \%, p=0.0031)$. Topical therapy was less frequently used for UC patients of the hospital without specialists ( $2 \%$ vs. $17 \%, p=0.013$ ). These results suggest that 5-ASA agents were not sufficiently utilized for patients in the hospital without specialists. For CD patients, the manner for prescribing 5 -ASA agents did not significantly differ between the two hospitals (Table 2).

\subsection{Comparison of Corticosteroids Use}

Oral corticosteroids were prescribed in $10 \%$ of the UC patients and in 7\% of the CD patients of the hospital with specialists, and in $27 \%$ of the UC patients and in $23 \%$ of the CD patients of the hospital without specialists (Table 3). Because many guidelines insist that long-term corticosteroids should be avoided in the treatment of IBD, the proportion of patients who continuously received corticosteroids for more than 6 months was investigated. Both in UC and CD patients, the proportion of patients receiving long-term corticosteroids was higher in the hospital without specialists than in the hospital with specialists (UC: $23 \%$ vs. $5 \%, p<0.0001, \mathrm{CD}: 23 \%$ vs. $4 \%, p=$ 0.012 , respectively).

Table 2. Use of 5-aminosalicylic acid.

\begin{tabular}{|c|c|c|c|c|c|}
\hline & \multicolumn{2}{|c|}{ Hospital with specialists } & \multicolumn{2}{|c|}{ Hospital without specialists } & \multirow[t]{2}{*}{$p$-value } \\
\hline UC patients & 174 & & 45 & & \\
\hline \multicolumn{6}{|l|}{ Oral administration } \\
\hline Salazosulfapyridine & 53 & $(30 \%)$ & 3 & $(7 \%)$ & \multirow[t]{2}{*}{$0.0022^{*}$} \\
\hline \multicolumn{5}{|l|}{ Mesalazine } & \\
\hline Pentasa $3 \mathrm{~g} /$ day $\leq$ or Asacol $3.6 \mathrm{~g} /$ day $\leq$ & 89 & $(51 \%)$ & 15 & $(33 \%)$ & \multirow{2}{*}{$<0.0001^{* *}$} \\
\hline Pentasa $3 \mathrm{~g} /$ day $>$ or Asacol $3.6 \mathrm{~g} /$ day $>$ & 26 & $(15 \%)$ & 21 & $(47 \%)$ & \\
\hline None & 6 & $(4 \%)$ & 6 & $(13 \%)$ & \\
\hline \multicolumn{6}{|l|}{ Topical (enema or suppository) } \\
\hline Yes & 29 & $(17 \%)$ & 1 & $(2 \%)$ & \multirow{2}{*}{0.013} \\
\hline No & 145 & $(83 \%)$ & 44 & $(98 \%)$ & \\
\hline CD patients & 65 & & 26 & & \\
\hline \multicolumn{6}{|l|}{ Oral administration } \\
\hline Salazosulfapyridine & 4 & $(6 \%)$ & 2 & $(8 \%)$ & \multirow{2}{*}{$1.0^{*}$} \\
\hline \multicolumn{5}{|l|}{ Pentasa } & \\
\hline Pentasa $3 \mathrm{~g} /$ day $\leq$ & 25 & $(38 \%)$ & 15 & $(58 \%)$ & \multirow{2}{*}{$0.082^{* *}$} \\
\hline Pentasa $3 \mathrm{~g} /$ day $>$ & 26 & $(40 \%)$ & 6 & $(23 \%)$ & \\
\hline None & 10 & $(15 \%)$ & 3 & $(12 \%)$ & \\
\hline
\end{tabular}

UC, ulcerative colitis; CD, Crohn's disease. Patients with 5-aminosalicylic acid allergy were excluded from this analysis. "Salazosulfapyridine use vs. mesalazine use; ${ }^{* *}$ Pentasa $3 \mathrm{~g} /$ day $\leq$ or Asacol $\leq 3.6 \mathrm{~g} /$ day vs. Pentasa $3 \mathrm{~g} /$ day $>$ or Asacol $>3.6 \mathrm{~g} /$ day, or none. 


\subsection{Comparison of Immunomodulators and Biologics Use}

Table 4 indicates the conditions of use of immunomodulators (AZA or 6-MP) and biologics (infliximab or adalimumab) in the two hospitals. Immunomodulators were less frequently used in the hospital without specialists (UC $+\mathrm{CD} ; 14 \%$ vs. $44 \%, p<0.0001$ ). The difference was markedly lower in UC patients of the hospital without specialists ( $8 \%$ vs. $46 \%, p<0.0001)$. Biologics in $\mathrm{CD}$ were used more frequently in the hospital with specialists $(46 \%$ vs. $15 \%, p=0.0083)$.

\section{DISCUSSION}

In this study, we demonstrated that IBD patients who were treated by an IBD non-specialist were likely to be in an uncontrolled disease status. In addition, those patients were likely to be provided medications inappropriately, e.g., insufficient doses of 5-ASA, longer corticosteoroids administration, and less frequent prescriptions of immunomodulators. Although the difference in clinical characteristics between the two groups may have affected the treatment strategy, the result that UC patients of the hospital without specialists were likely to show extensive colitis may also indicate that inappropriate treatment strategy extended the area of active disease. Details of differences in medical care for IBD patients between specialists and non-specialists elucidated in this study can be helpful in education of doctors and consequently improvement of clinical care for IBD patients.

Table 3. Use of corticosteroids.

\begin{tabular}{|c|c|c|c|c|c|}
\hline & \multicolumn{2}{|c|}{ Hospital with specialists } & \multicolumn{2}{|c|}{ Hospital without specialists } & $p$-value \\
\hline \multicolumn{5}{|c|}{ 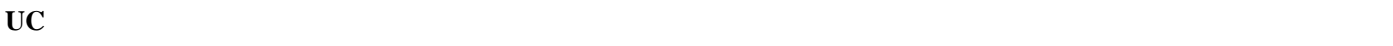 } & \\
\hline No & 168 & $(90 \%)$ & 35 & $(73 \%)$ & \multirow{4}{*}{$0.0001^{*}$} \\
\hline Yes & & & & & \\
\hline$<6$ months & 9 & $(5 \%)$ & 2 & $(4 \%)$ & \\
\hline$\geq 6$ months & 10 & $(5 \%)$ & 11 & $(23 \%)$ & \\
\hline \multicolumn{6}{|l|}{ CD } \\
\hline No & 63 & $(93 \%)$ & 20 & $(77 \%)$ & \multirow{4}{*}{$0.012^{*}$} \\
\hline Yes & & & & & \\
\hline$<6$ months & 2 & $(3 \%)$ & 0 & $(0 \%)$ & \\
\hline$\geq 6$ months & 3 & $(4 \%)$ & 6 & $(23 \%)$ & \\
\hline
\end{tabular}

UC, ulcerative colitis; CD, Crohn's disease. ${ }^{*}$ No or $<6$ months vs. $\geq 6$ months.

Table 4. Immunomodulators and biologics use.

\begin{tabular}{|c|c|c|c|c|c|}
\hline & \multicolumn{2}{|c|}{ Hospital with specialists } & \multicolumn{2}{|c|}{ Hospital without specialists } & $p$-value \\
\hline \multicolumn{6}{|c|}{ Immunomodulators } \\
\hline \multicolumn{6}{|l|}{ UC } \\
\hline Yes & 85 & $(46 \%)$ & 4 & $(8 \%)$ & \multirow{2}{*}{$<0.0001$} \\
\hline No & 102 & $(56 \%)$ & 44 & $(92 \%)$ & \\
\hline \multicolumn{6}{|l|}{ CD } \\
\hline Yes & 28 & $(41 \%)$ & 6 & $(23 \%)$ & \multirow{2}{*}{0.10} \\
\hline No & 40 & $(58 \%)$ & 20 & $(77 \%)$ & \\
\hline \multicolumn{6}{|c|}{ Biologics } \\
\hline \multicolumn{6}{|l|}{ UC } \\
\hline Yes & 11 & $(6 \%)$ & 1 & $(2 \%)$ & \multirow{2}{*}{0.47} \\
\hline No & 176 & $(94 \%)$ & 47 & $(98 \%)$ & \\
\hline \multicolumn{6}{|l|}{ CD } \\
\hline Yes & 31 & $(46 \%)$ & 4 & $(15 \%)$ & \multirow{2}{*}{0.0083} \\
\hline No & 37 & $(54 \%)$ & 22 & $(85 \%)$ & \\
\hline
\end{tabular}

UC, ulcerative colitis; CD, Crohn's disease. 
Many studies have shown that IBD benefited considerably from treatment with 5-ASA $[19,20]$. Several studies showed that the efficacy of 5-ASA for UC is dosedependent [21-23]. In addition, a recent guideline indicated that greater clinical improvement for UC is associated with doses $>3 \mathrm{~g}$ /day of mesalazine [14]. In this context, our results showed that 5-ASA prescribed by non-specialists of IBD was not sufficient. These physicians may be fearful of adverse events due to a high-dose 5-ASA, although it has been shown that the incidence of adverse events of 5-ASA is not dose-dependent [21]. Otherwise, they reduced doses of 5-ASA early after achieving remission. Because patients who were treated by a non-specialist were likely to have more active disease, those doctors should have prescribed more doses of 5-ASA and for longer duration.

IBD specialists were more likely than non-specialists to prescribe salazosulfapyridine for UC patients. Previous studies have showed that salazosulfapyridine is more effective for UC, but more frequently show adverse effects such as headache, rash, nausea, and liver and renal dysfunction than mesalazine [24-26]. Because specialists were familiar with handling these adverse effects, they could prescribe this agent with the expectation of deriveing a better response than with mesalazine.

Topical therapy of 5-ASA is effective for UC when used either as a topical therapy alone or used in combination with oral 5-ASA [27]. Because topical administration is occasionally burdensome for patients, adequate education and explanation for the patients are necessary. It is more likely that patients would accept the use of topical preparations when the instructions and explanations are provided by the specialists than the non-specialists. Thus, for 5-ASA for IBD patients, guidelines may have to stipulate the optimal dose and the optimal way of application in more detail, including handling of salazosulfapyridine and topical therapy.

The difference in oral corticosteroids use was one of the most striking results of this study. Corticosteroids are potent anti-inflammatory agents for moderate to severe relapses of both UC and CD. However, long-term and/or repeated administrations of corticosteroids induce various adverse events including diabetes, osteoporosis, ophthalmologic diseases, and psychiatric disorders. Therefore, all of the guidelines insist that long-term and/or repeated use of corticosteroids should be avoided for IBD patients. Nevertheless, non-specialists were likely to use corticosteroids in spite of the guidelines. Several reasons may account for this inappropriate practice. First, a considerable part of IBD patients are likely to go into a steroid-dependent course unless appropriate steroid-sparing medications are given. In fact, Faubion et al. reported that $22 \%$ of UC patents and $28 \%$ of CD patients fell into a steroid-dependent course [28]. Awkwardness of ster- oid-sparing agents such as AZA and 6-MP facilitate steroid-dependence. Next, maintenance therapy with corticosteroids is not so rare when treating other diseases than IBD. In fact, maintenance with long-term corticosteroids is allowed in the treatment of autoimmune hepatitis and immune thrombocytopenic purpura [29,30]. IBD experts must inform non-specialists of appropriate methods of using corticosteroids with consideration of the particular features for IBD treatment. In addition, it should be known that UC patients have a chance of cure without any more corticosteroids by undergoing colectomy.

In this study, IBD patients of the hospital without specialists were more likely to be treated by a psychiatrist than patients of the hospital with specialists (data not shown). Patients who suffer from a long-term incurable disease with difficult symptoms may be likely to develop psychiatric disorders. However, there may be patients who had psychiatric disorders induced by inappropriate use of corticosteroids.

Immunomodulators (AZA or 6-MP) are widely used in maintenance therapy for both UC and CD. The use of these agents is particularly indispensable for patients with a steroid-dependent course. However, these agents can easily cause adverse events including leukocytopenia, thrombocytopenia, alopecia, and gastrointestinal uncomfortable symptoms, which hamper prescriptions by nonspecialists. These agents have more difficulties in eliciting responses: very slow onset of effectiveness and diversity of proper doses among subjects. The onset of the effects of these agents usually takes two or three months. Such long periods make non-specialist doctors unaware of the efficacy of the agents.

The diversity in proper dose of the agents is a very challenging problem. In Western countries, the recommended maintenance dose of AZA is $2-2.5 \mathrm{mg} / \mathrm{kg} /$ day and that of 6-MP is $0.75-1.5 \mathrm{mg} / \mathrm{kg} /$ day [31]. For Japanese patients, however, the appropriate maintenance doses were lower: 50 - $100 \mathrm{mg} /$ day in AZA and $30-50 \mathrm{mg} /$ day in 6-MP $[32,33]$. Dose diversity within ranges of lower amounts makes adjustment of doses more difficult. Moreover, an excess dose of the agents can easily cause adverse events. Therefore, dose adjustment of the agents may be more difficult for Japanese doctors than Western doctors. Although measurement of 6-thioguanine levels and allele diversity of thiopurine methyltransferase has been reported to be helpful in determining doses of the agents [34], these are not routinely examined in the majority of hospitals. In addition, several reports suggested that these indices are not reliable, particularly for Japanese patients $[35,36]$. Thus, many obstacles have caused non-specialist doctors to hesitate about issuing prescripttions for these agents. However, it should be noticed that specialist doctors more frequently encounter severe adverse events due to $\mathrm{AZA} / 6-\mathrm{MP}$ in their patients than 
non-specialist doctors (data not shown). It seems an additional problem is that 6-MP is not covered by the health insurance in Japan, although 6-MP generally causes less frequent adverse events and is more tolerable in IBD patients than AZA [36-38].

Biologics were more frequently used for $\mathrm{CD}$ patients in the hospital with specialists. This suggests that the proportion of the patients with more severe activity who require biologics therapy was larger in the hospital with specialists. However, an additional consideration is that non-specialist doctors prescribed corticosteroids inadequately for severe $\mathrm{CD}$ patients. Because biologics use for UC only became available in 2010 in Japan, the use was limited in both institutes.

There are several potential limitations of this study, which preclude broad generalizations concerning the quality of care of patients with IBD. First, areas where each hospital located are different. The difference may cause biases in patient demographics and manners in receiving medical care including medications. In this context, disease duration of the patients of the hospital without specialists was shorter than that of the patients of the hospital with specialists. However, this result may indicate that patients who were treated by a non-specialist had hoped to visit other hospitals. Second, because this study was performed in Japan, direct generalizations of the results to other countries may not be valid. However, the many guidelines issued in Western countries in itself suggests the paucity of IBD specialists even in those countries. Moreover, our results would be particularly valuable in Asian countries where IBD patients are currently showing an increasing trend.

In conclusion, our study found that the IBD patients of the hospital without specialists were not well-controlled and were not prescribed therapeutic drugs appropriately when compared to the patients of the hospital with specialists. Many parallel guidelines are not necessary. Fostering and placement of the IBD specialist is an urgent problem in countries where IBD patients are increasing as well as in Western countries. In addition, to verify our findings, multicentric surveillance studies for medical care for IBD would be expected.

\section{REFERENCES}

[1] Talley, N.J., Abreu, M.T., Achkar, J.P., et al. (2011) An evidence-based systematic review on medical therapies for inflammatory bowel disease. American Journal of Gastroenterology, 106, S2-S25. doi:10.1038/ajg.2011.58

[2] Molodecky, N.A., Soon, I.S., Rabi, D.M., et al. (2011) Increasing incidence and prevalence of the inflammatory bowel diseases with time, based on systematic review. Gastroenterology, 142, 46-54.

[3] Loftus Jr., E.V. (2004) Clinical epidemiology of inflammatory bowel disease: Incidence, prevalence, and envi- ronmental influences. Gastroenterology, 126, 1504-1517. doi:10.1053/j.gastro.2004.01.063

[4] Ahuja, V. and Tandon, R.K. (2010) Inflammatory bowel disease in the Asia-Pacific area: A comparison with developed countries and regional differences. Journal of Digestive Diseases, 11, 134-147.

doi:10.1111/j.1751-2980.2010.00429.x

[5] Yao, T., Matsui, T. and Hiwatashi, N. (2000) Crohn's disease in Japan: Diagnostic criteria and epidemiology. Diseases of the Colon \& Rectum, 43, S85-S93. doi:10.1007/BF02237231

[6] Yamamoto, S., Nakase, H., Mikami, S., et al. (2008) Long-term effect of tacrolimus therapy in patients with refractory ulcerative colitis. Alimentary Pharmacology \& Therapeutics, 28, 589-597.

doi:10.1111/j.1365-2036.2008.03764.x

[7] Colombel, J.F., Sandborn, W.J., Rutgeerts, P., et al. (2007) Adalimumab for maintenance of clinical response and remission in patients with Crohn's disease: The CHARM trial. Gastroenterology, 132, 52-65. doi:10.1053/i.gastro.2006.11.041

[8] Ogata, H., Matsui, T., Nakamura, M., et al. (2006) A randomised dose finding study of oral tacrolimus (FK506) therapy in refractory ulcerative colitis. Gut, 55, 12551262. doi:10.1136/gut.2005.081794

[9] Shibolet, O., Regushevskaya, E., Brezis, M. and SoaresWeiser K. (2005) Cyclosporine A for induction of remission in severe ulcerative colitis. Cochrane Database of Systematic Reviews, 25, Article ID: CD004277.

[10] Rutgeerts, P., Sandborn, W.J., Feagan, B.G., et al. (2005) Infliximab for induction and maintenance therapy for ulcerative colitis. New England Journal of Medicine, 353, 2462-2476. doi:10.1056/NEJMoa050516

[11] Rutgeerts, P., Van Assche, G. and Vermeire, S. (2004) Optimizing anti-TNF treatment in inflammatory bowel disease. Gastroenterology, 126, 1593-1610. doi:10.1053/j.gastro.2004.02.070

[12] Kornbluth, A. and Sachar, D.B. (2010) Ulcerative colitis practice guidelines in adults: American College Of Gastroenterology, Practice Parameters Committee. American Journal of Gastroenterology, 105, 501-523. doi:10.1038/ajg.2009.727

[13] Lichtenstein, G.R., Hanauer, S.B. and Sandborn, W.J. (2009) Management of Crohn's disease in adults. American Journal of Gastroenterology, 104, 465-483.

[14] Mowat, C., Cole, A., Windsor, A., et al. (2011) Guidelines for the management of inflammatory bowel disease in adults. Gut, 60, 571-607. doi:10.1136/gut.2010.224154

[15] Matsui, T. and Ueno, F. (2010) Crohn's disease practice guidelines in Japan. Nihon Shokakibyo Gakkai Zasshi, 107, 1887-1896.

[16] Hibi, T., Ueno, F., Matsuoka, K. and Lee, T. (2010) Guidelines for the management of ulcerative colitis in Japan. IBD Research, 4, 189-239.

[17] Reddy, S.I., Friedman, S., Telford, J.J., Strate, L., Ookubo, R. and Banks, P.A. (2005) Are patients with inflammatory bowel disease receiving optimal care? American Journal of Gastroenterology, 100, 1357-1361. 
doi:10.1111/j.1572-0241.2005.40849.x

[18] Stange, E.F., Travis, S.P., Vermeire, S., et al. (2006) European evidence based consensus on the diagnosis and management of Crohn's disease: Definitions and diagnosis. Gut, 55, i1-i15. doi:10.1136/gut.2005.081950a

[19] Bergman, R. and Parkes, M. (2006) Systematic review: The use of mesalazine in inflammatory bowel disease. Alimentary Pharmacology \& Therapeutics, 23, 841-855. doi:10.1111/j.1365-2036.2006.02846.x

[20] Sutherland, L. and Macdonald, J.K. (2006) Oral 5-aminosalicylic acid for induction of remission in ulcerative colitis. Cochrane Database of Systematic Reviews, 3, Article ID: CD000543.

[21] Yamamoto, T., Umegae, S. and Matsumoto, K. (2011) High-dose mesalazine treatment for ulcerative colitis patients who relapse under low-dose maintenance therapy. Digestive and Liver Disease, 43, 386-390. doi:10.1016/j.dld.2010.11.016

[22] Hiwatashi, N., Suzuki, Y., Mitsuyama, K., Munakata, A. and Hibi, T. (2011) Clinical trial: Effects of an oral preparation of mesalazine at $4 \mathrm{~g}$ /day on moderately active ulcerative colitis. A phase III parallel-dosing study. Journal of Gastroenterology, 46, 46-56. doi:10.1007/s00535-010-0308-3

[23] Hanauer, S.B., Sandborn, W.J., Kornbluth, A., et al. (2005) Delayed-release oral mesalamine at $4.8 \mathrm{~g} /$ day (800 $\mathrm{mg}$ tablet) for the treatment of moderately active ulcerative colitis: The ASCEND II trial. American Journal of Gastroenterology, 100, 2478-2485. doi:10.1111/j.1572-0241.2005.00248.x

[24] Ransford, R.A. and Langman, M.J. (2002) Sulphasalazine and mesalazine: Serious adverse reactions re-evaluated on the basis of suspected adverse reaction reports to the Committee on Safety of Medicines. Gut, 51, 536-539. doi:10.1136/gut.51.4.536

[25] Loftus Jr., E.V., Kane, S.V. and Bjorkman, D. (2004) Systematic review: Short-term adverse effects of 5-aminosalicylic acid agents in the treatment of ulcerative colitis. Alimentary Pharmacology \& Therapeutics, 19, 179189. doi:10.1111/j.0269-2813.2004.01827.x

[26] Sutherland, L. and Macdonald, J.K. (2006) Oral 5-aminosalicylic acid for maintenance of remission in ulcerative colitis. Cochrane Database of Systematic Reviews, 4, Article ID: CD000544.

[27] Marteau, P., Probert, C.S., Lindgren, S., et al. (2005) Combined oral and enema treatment with Pentasa (mesalazine) is superior to oral therapy alone in patients with extensive mild/moderate active ulcerative colitis: A randomised, double blind, placebo controlled study. Gut, 54, 960-965. doi:10.1136/gut.2004.060103

[28] Faubion Jr., W.A., Loftus Jr., E.V., Harmsen, W.S., Zinsmeister, A.R. and Sandborn, W.J. (2001) The natural history of corticosteroid therapy for inflammatory bowel disease: A population-based study. Gastroenterology, 121, 255-260. doi:10.1053/gast.2001.26279

[29] Strassburg, C.P. and Manns, M.P. (2011) Therapy of autoimmune hepatitis. Best Practice \& Research Clinical Gastroenterology, 25, 673-687. doi:10.1016/j.bpg.2011.08.003

[30] George, J.N. (2006) Management of patients with refractory immune thrombocytopenic purpura. Journal of Thrombosis and Haemostasis, 4, 1664-1672. doi:10.1111/j.1538-7836.2006.02013.x

[31] Dignass, A., Van Assche, G., Lindsay, J.O., et al. (2010) The second European evidence-based Consensus on the diagnosis and management of Crohn's disease: Current management. Journal of Crohn's and Colitis, 4, 28-62. doi:10.1016/j.crohns.2010.07.001

[32] Hibi, T., Naganuma, M., Kitahora, T., Kinjyo, F. and Shimoyama, T. (2003) Low-dose azathioprine is effective and safe for maintenance of remission in patients with ulcerative colitis. Journal of Gastroenterology, 38, 740746. doi:10.1007/s00535-003-1139-2

[33] Hibi, T., Iwao, Y., Yajima, T., et al. (1995) Immunosuppressive agents in the treatment of Crohn's disease and ulcerative colitis. Journal of Gastroenterology, 30, 121123.

[34] Dubinsky, M.C., Yang, H., Hassard, P.V., et al. (2002) 6-MP metabolite profiles provide a biochemical explanation for 6-MP resistance in patients with inflammatory bowel disease. Gastroenterology, 122, 904-915. doi:10.1053/gast.2002.32420

[35] Takatsu, N., Matsui, T., Murakami, Y., et al. (2009) Adverse reactions to azathioprine cannot be predicted by thiopurine S-methyltransferase genotype in Japanese patients with inflammatory bowel disease. Journal of Gastroenterology and Hepatology, 24, 1258-1264. doi:10.1111/j.1440-1746.2009.05917.x

[36] Hindorf, U., Johansson, M., Eriksson, A., Kvifors, E. and Almer, S.H. (2009) Mercaptopurine treatment should be considered in azathioprine intolerant patients with inflammatory bowel disease. Alimentary Pharmacology \& Therapeutics, 29, 654-661. doi:10.1111/j.1365-2036.2008.03925.x

[37] Kuriyama, M., Kato, J., Suzuki, H., et al. (2010) Tolerability and usefulness of mercaptopurine in azathioprine-intolerant Japanese patients with ulcerative colitis. Digestive Endoscopy, 22, 289-296. doi:10.1111/j.1443-1661.2010.01009.x

[38] Domenech, E., Nos, P., Papo, M., Lopez-San Roman, A., Garcia-Planella, E. and Gassull, M.A. (2005) 6-mercaptopurine in patients with inflammatory bowel disease and previous digestive intolerance of azathioprine. Scandinavian Journal of Gastroenterology, 40, 52-55. 